\title{
Pteridaceae da Reserva Ecológica de Macaé de Cima, Nova Friburgo, Rio de Janeiro, Brasil
}

\author{
Jefferson Prado ${ }^{1}$
}

\begin{abstract}
Resumo
(Pteridaceae da Reserva Ecológica de Macaé de Cima, Nova Friburgo, Rio de Janeiro, Brasil) No presente trabalho é apresentado o tratamento taxonômico da família Pteridaceae na Reserva Ecológica de Macaé de Cima. A família está representada na área por três espécies e dois gêneros: Doryopteris acutiloba (Prantl) Diels, Pteris decurrens C. Presl e P. deflexa Link. Para cada espécie são apresentados comentários, descrições, distribuição geográfica e ilustrações, bem como uma chave para identificação das mesmas.
\end{abstract}

Palavras-chave: Doryopteris, flora, pteridófitas, Pteris, taxonomia.

\section{Abstract}

(Pteridaceae of ReservaEcológica de Macaé de Cima, Nova Friburgo, Rio de Janeiro, Brazil) In this paper is presented the taxonomic treatment of the family Pteridaceae in the Reserva of Macaé de Cima. In the area the family is represented by three species and two genera: Doryopteris acutiloba (Prantl) Diels, Pteris decurrens C. Presl and $P$. deflexa Link. For each species are presented comments, descriptions, distribution, and illustrations as well as a key for its identification.

Key-words: Doryopteris, flora, pteridophytes, Pteris, taxonomy.

\section{INTRODUÇÃO}

Este estudo é parte do levantamento florístico que vem sendo conduzido pelo Jardim Botânico do Rio de Janeiro, desde 1988, na área da Reserva Ecológica de Macé de Cima. Alguns dados relacionados as pteridófitas já foram publicados nos dois primeiros volumes desta flora (Lima \& Guedes-Bruni 1994, 1996) e incluíram a listagem de todas as espécies do grupo na Reserva e o tratamento taxonômico das famílias Cyatheaceae e Dicksoniaceae (Sylvestre \& Kurtz 1994a, b), Marattiaceae (Mynssen \& Sylvestre 1996), Ophioglossaceae (Mynssen 1996), Schizaeaceae (Santos \& Sylvestre 1996) e Vittariaceae (Santos 1996).

Dando continuidade à publicação desses resultados, é apresentado no presente trabalho o estudo taxonômico da família Pteridaceae.

\section{Material e Métodos}

A área da Reserva Ecológica de Macé de Cima pertence ao Município de Nova Friburgo e está situada nas encostas da Serra do Mar, na região das serras de Macaé, São João e Taquaruçu $\left(22^{\circ} 21^{\prime}-22^{\circ} 28^{\prime} \mathrm{Se} 42^{\circ} 27^{\prime}-42^{\circ} 35^{\prime} \mathrm{W}\right)$. Seu relevo é bastante ondulado, com vales estreitos formados por rochas metamórficas do pré-cambriano e sua altitude varia de 880 a $1.720 \mathrm{~m}$. A vegetação predominante é a floresta pluvial atlântica montana (Lima \& Guedes-Bruni 1994). As plantas estudadas neste trabalho foram coletadas de acordo com as técnicas usuais e encontram-se depositadas nos herbários GUA e RB. O sistema de classificação adotado para a família foi o de Tryon \& Tryon (1982) e Tryon (1986). Os nomes dos autores dos táxons foram abreviados segundo Pichi-Sermolli (1996).

\section{Resultados e Discussão \\ Pteridaceae}

Plantas terrestres ou rupícolas. Caule ereto ou decumbente, curto a longo-reptante, pouco desenvolvido ou robusto, com um sifonostelo ou dictiostelo, com tricomas ou escamas. Frondes monomorfas a dimorfas, de $3 \mathrm{~cm}$ até $1,5 \mathrm{~m}$ compr.; pecíolo sem estípulas; lâmina inteira, pedada, palmada, pinatífida, ou geralmente pinada, circinada ou parcialmente circinada nos brotos. Soros sobre a superfície abaxial e na margem da lâmina, sobre uma comissura vascular; indúsio formado pela

Artigo recebido em 10/2004. Aceito para publicação em 03/2005.

${ }^{1}$ Instituto de Botânica. Cx. Postal 4005. CEP 01061-970. São Paulo, SP. 
margem da lâmina recurvada, delgada; esporângios geralmente pedicelados ou curtopedicelados, pedicelo geralmente com 5 fileiras de células ou com 2-3 fileiras de células, ânulo vertical, interrompido pelo pedicelo; esporos triletes, sem colorofila. Gametófito epígeo, clorofilado, obcordado a reniforme, algumas vezes assimétrico, espessado ou não na região central, glabro ou às vezes com tricomas glandulares, arquegônios sobre a superfície abaxial, freqüentementes na região da depressão central, anterídios tri-celulados também sobre a superfície inferior, separados dos arquegônios, ou, às vezes, próximos da margem.

De acordo com Tryon \& Tryon (1982), Pteridaceae é uma família grande, diversificada e com ampla distribuição geográfica. É constituída por cerca de 35 gêneros e destes, 22 ocorrem nas Américas. Caracteriza-se basicamente pelos esporângios na face abaxial da lâmina, sobre as nervuras levemente modificadas ou não, ou na margem da lâmina e, às vezes, recobertos por um indúsio, formado pela margem da lâmina modificada (pseudo-indúsio). Os esporos são triletes e sem colorofila. Onúmero cromossômico varia entre 29 e 30 (ou múltiplos destes).
Ainda segundo Tryon \& Tryon (1982), a família pode ser dividida em seis tribos. Posteriormente, Tryon (1986) elevou essas tribos à categoria de subfamílias: Adiantoideae, Ceratopteridoideae, Cheilanthoideae, Platyzomatoideae, Pteridoideaee Taenitidoideae.

Em tratamentos mais recentes para a família (Moran \& Yatskievych 1995 e Smith 1995), outros cinco gêneros têm sido reconhecidos, totalizando a ocorrência de 27 gêneros para a América tropical. Esses gêneros foram na verdade segregados de outros maiores, tais como: Argyrochosma (J. Sm.) Windham (a partir de Notholaena R. Br.), Aleuritopteris Fée (de Cheilanthes Sw.), Astrolepis Benham \& Windham (de Cheilanthes e Notholaena), Cheilopecton Fée (de Doryopteris J. Sm., Cheilanthes e Pellaea Link) e Mildella Trevis. (de Pteris L.).

$\mathrm{Na}$ área da Reserva Ecológica de Macaé de Cima, a família está representada por dois gêneros: Doryopteris e Pteris, com um total de três espécies.

O gênero Doryopteris foi revisado por Tryon (1942) e para as espécies brasileiras de Pteris, tratadas no presente estudo, existem os trabalhos de Lellinger (1997) e Prado \& Windisch (2000).

\section{Chave para identificação das espécies}

1. Lâmina inteira, lobada ou pinatífida

1. Doryopteris acutiloba

1'. Lâmina tripartida, 1-3-pinado-pinatífida

2. Nervuras parcialmente areoladas

2. Pteris decurrens

2'. Nervuras livres 3. Pteris deflexa

1. Doryopteris acutiloba (Prantl) Diels in Engl. \& Prantl, Nat. Pfl. 1(4): 269. 1899.

Pellaea acutiloba Prantl, Engl. Bot. Jahrb. 3: 425. 1882.

Figura 1a

Plantas terrestres ou rupícolas. Caule curto, ascendente, ca. $5 \mathrm{~mm}$ diâm., com escamas linearlanceoladas, castanho-claras, com faixa central esclerificada, 2-5 mm compr. Frondes dimorfas, eretas a patentes, 4-60 cm compr.; pecíolo cilíndrico, com 2 feixes vasculares na base, com escamas na base, iguais às do caule, glabro em direção à lâmina; pecíolo da fronde estéril 8-40 cm compr., ca. 1 mm diâm.; lâmina da fronde estéril inteira, cartácea, glabra em ambas as faces, lobada a pinatífida, 3-5 lobos deltóides, hastados, ápice agudo, margem castanho-clara a esbranquiçada; venação aberta, nervuras simples ou furcadas, ápice em forma de clava; pecíolo da fronde fértil $12-20 \mathrm{~cm}$ compr., ca. 1 mm diâm.; lâmina da fronde fértil inteira, cartácea, glabra em ambas as faces, pinatífida, 7 lobos linear-lanceolados, ápice agudo, o central decorrente, margem revoluta modificada como 
indúsio; venação com as extremidades unidas poruma nervura coletora marginal. Soros marginais, sobre uma comissura vascular; esporos triletes, perisporo ruguloso e esbranquiçado.

Material examinado: $L$. S. Sylvestre et al. 361 (RB).

Hábitat: Geralmente ocorre em locais sombreados, no interior de mata. Em Macaé de Cima foi encontrada crescendo no solo.

Distribuição geográfica: Endêmica do Sudeste e Sul do Brasil (Rio de Janeiro, Paraná e Santa Catarina).

Doryopteris acutiloba pode ser eventualmente confundida com $D$. lomariacea Klotzsch, entretanto esta última difere por apresentar lâmina coriácea e os últimos segmentos mais amplos e com ápice arredondado. Quando fértil, D. acutiloba pode ser facilmente reconhecida pelos esporos comperisporo esbranquiçado.

2. Pteris decurrens C. Presl, Del. Prag. 1: 183. 1822.

Figura 1b-e

Plantas terrestres. Rizoma ereto, compacto e curto, lenhoso, ca $1 \mathrm{~cm}$ diâm., densamente revestido por escamas 1-6 mm compr., lanceoladas, com faixa central castanho-escura, brilhante. Frondes $60 \mathrm{~cm}$ até $2 \mathrm{~m}$ compr., 20$80 \mathrm{~cm}$ larg., monomorfas, escandentes; pecíolo $25-80 \mathrm{~cm}$ compr., 2-3 mm diâm., profundamente 2-3 vezes sulcado na face adaxial, castanhoescuro a castanho-claro, às vezes amarelado, com escamas na base, glabro ou esparsamente pubescente, indumento formado por tricomas alvos, curtos, unisseriados, superfície lisa; lâmina tripartida, triangular, cartácea, esparsamente pubescente, tricomas na raque, costa $\mathrm{e}$ cóstula, 1-pinado-pinatífida (raramente 2-pinadopinatífida), $30-80$ × 20-70 cm, 3-6 pares de pinas, opostas a subopostas, oblongo-lanceoladas a elípticas, sésseis ou pecioluladas (pinas basais), base do lado basiscópico decorrente na raque, costa sulcada na face adaxial e proeminente na face abaxial, par de pinas basais furcado, pinatífido, porção basiscópica da furca levemente voltada para a base da fronde, 12-
20 x 2-4,5 cm, porção acroscópica da furca $15-30 \times 3-8 \mathrm{~cm}$, raque $15-60 \times 0,1-0,2 \mathrm{~cm}, 1$ vez sulcada na face adaxial, pinas medianas $15-30$ x 3-7 cm, inseridas em ângulo agudo na raque, pinas distais $10-20 \times 2-4,5 \mathrm{~cm}$, voltadas em direção ao ápice da fronde, base pronunciadamente decorrente na raque, pina apical 10$25 \times 3-7 \mathrm{~cm}$, profundamente pinatífida, base longamente decorrente até o par de pinas distais, segmentos basais das pinas menores que os segmentos medianos, agudos ou obtusos, alternos, lineares a lanceolados, brevemente falciformes, margem inteira nas regiões basal e mediana, denteada no ápice dos segmentos, segmento apical lobado ou pinatífido, cóstula proeminente na face abaxial, enseio entre os segmentos arredondado, às vezes biangulado; venação parcialmente areolada, com uma aréola alongada mais uma pequena aréola junto à costa, entre duas cóstulas adjacentes, areolada ao longo da cóstula e com nervuras livres acima das aréolas, próximas da margem dos segmentos, ápice das nervuras levemente espessado em forma de clava, na fronde fértil o ápice das nervuras são unidos por uma nervura coletora marginal. Soro marginal, interrompido na região do enseio e ausente no ápice dos segmentos.

Material examinado: L. S. Sylvestre 144(RB). Hábitat: Ocorre preferencialmente em florestas úmidas de regiões serranas, à margem de córregos, rios e em encostas íngremes, em locais sombreados.

Distribuição geográfica: Bahia até o Rio Grande do Sul. Esta espécie apresenta distribuição restrita à América do Sul e, além do Brasil, ocorre na Colômbia, Venezuela, Equador, Peru, Bolívia e Chile.

Pteris decurrens possui a base das pinas distais e apical decorrentes na raque. Esta característica, aliada ao padrão de venação areolado, com duas aréolas entre duas cóstulas adjacentes (uma aréola grande e alongada, mais uma pequena aréola), permitem seu fácil reconhecimento. Além disto, o par de pina basal é uma vez furcado. 

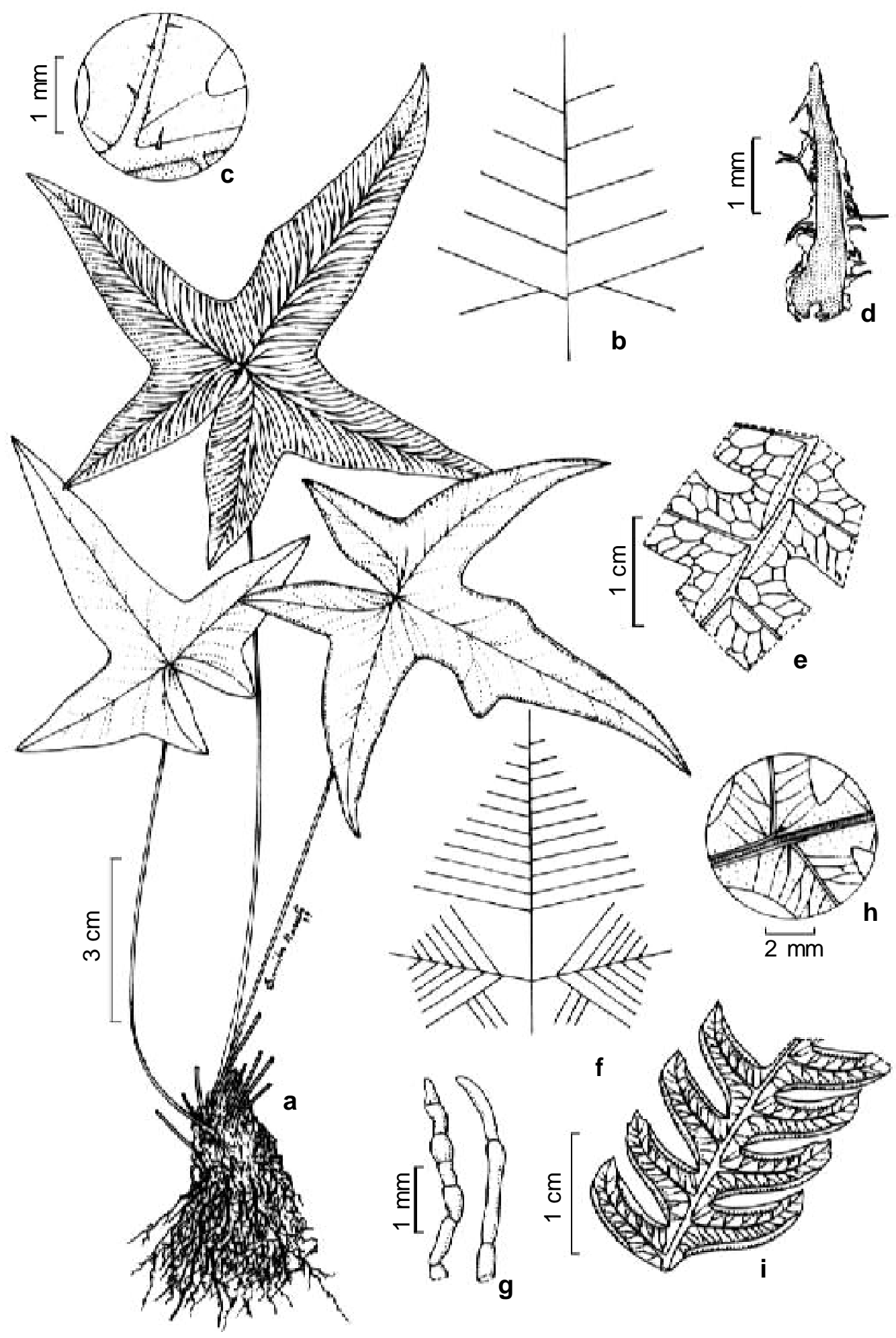

Figura 1 - a - Doryopteris acutiloba (Prantl) Diels: hábito. b-e - Pteris decurrens C. Presl: b - padrão de divisão da lâmina; $\mathrm{c}$ - detalhe do indumento de tricomas na face abaxial da lâmina; $\mathrm{d}$ - escama do rizoma; e - detalhe das nervuras. $\mathrm{f}-\mathrm{i}$ - Pteris deflexa Link: $\mathrm{f}$ - padrão de divisão da lâmina; $\mathrm{g}$ - tricomas da lâmina; $\mathrm{h}$ - detalhe mostrando os lacínios na base da cóstula; $\mathrm{i}$ - detalhe das nervuras. 
3. Pteris deflexa Link, Hort. Berol. 2: 30. 1833. Figura 1f-i

Plantas terrestres. Rizoma curto e compacto, reptante a ereto, lenhoso, $1-8 \mathrm{~cm}$ diâm., com muitas raízes fibrosas, recoberto por escamas, 2-5 mm compr., lanceoladas, com faixa central castanho-escuras, brilhante, constituída por células alongadas e com paredes espessas, base brevemente alargada, margem hialina, delgada, com tricomas unicelulares a pluricelulares, unisseriados. Frondes $0,5 \mathrm{~cm}$ até $2,5 \mathrm{~m}$ compr., $12-60 \mathrm{~cm}$ larg. monomorfas a subdimorfas (pinas da fronde fértil mais estreitas), decumbentes; pecíolo $18-25 \mathrm{~cm}$ compr., $0,1-1,5 \mathrm{~cm}$ diâm., 1 vez sulcado na face adaxial, castanho-claro a castanho-escuro na base, amarelado nas regiões mediana e apical, com escamas na base, glabro, superfície lisa; lâmina tripartida, deltóide, cartácea a subcoriácea, 1-3-pinado-pinatífida na base, 1-pinadopinatífida na porção apical, $21 \mathrm{~cm}$ a $1 \mathrm{~m}$ compr., 12-60 cm larg., 6-12 pares de pinas, opostas, subopostas até alternas, longo-lanceoladas ou elíptico-alongadas, sésseis ou pecioluladas, base assimétrica, cuneada, peciólulo quando presente 1 vez sulcado na face adaxial e brevemente alado, costa $1 \mathrm{vez}$ sulcada na face adaxial e proeminente na face abaxial, sinuosa, glabra ou com tricomas alvos, esparsos, unisseriados, pinas basais 11-64 x 5,5-25 cm, 1-2-pinadopinatífidas, raque $40-60 \times 0,1-1 \mathrm{~cm}, 1 \mathrm{vez}$ sulcada na face adaxial, pinas medianas 7,0$18 \times 1,7-2,5 \mathrm{~cm}$, pinatífidas, inseridas em ângulo agudo na raque; pinas distais $4-8 \times 1-1,5 \mathrm{~cm}$, voltadas em direção ao ápice da fronde, pina apical 9-15 x 2-3 cm, profundamente pinatífida, segmentos alternos, falciformes ou deltóides ou lanceolados, voltados em direção ao ápice de fronde, pina ou pínula, margem inteira, lisa ou denteada ou serrulada no ápice dos segmentos, ápice agudo, às vezes apiculado, cóstula com lacínios na base no lado adaxial e proeminente na face abaxial, segmento apical longamente atenuado em direção ao ápice, enseio entre os segmentos em geral agudo ou arredondado ou às vezes biangulado; venação aberta, nervuras simples ou furcadas, chegando até a margem dos segmentos, com ápice espessado em forma de clava. Soro interrompido na região do enseio e ausente no ápice dos segmentos.

Material examinado: J. P. P. Carauta et al. 2709 (GUA); L. S. Sylvestre et al. 395 (RB). Hábitat: É uma espécie facilmente encontrada em regiões serranas do sudeste do Brasil, ocorrendo em locais úmidos, desde os vales dos rios e córregos até as encostas íngremes. Distribuição geográfica: Mato Grosso, Bahia, Minas Gerais, Rio de Janeiro, São Paulo, Paraná, Santa Catarina. Apresenta-se amplamente distribuída na América tropical, ocorrendo desde o México, Caribe até a Argentina.

Pteris deflexa distingue-se pelas nervuras livres, costa sinuosa na porção apical das pinas e cóstula na face adaxial com lacínios na base.

\section{REFERÊNCIAS Bibliográficas}

Lellinger, D. B. 1997. Pteris deflexa and its allies. American Fern Journal 87(2): 66-70.

Lima, M. P. M. \& Guedes-Bruni, R. R. (orgs.). 1994. Reserva ecológica de Macaé de Cima, Nova Friburgo-RJ, aspectos florísticos das espécies vasculares. Jardim Botânico do Rio de Janeiro, Rio de Janeiro, v. 1.

Lima, M. P. M. \& Guedes-Bruni, R. R. (orgs.). 1996. Reserva ecológica de Macaé de Cima, Nova Friburgo-RJ, aspectos florísticos das espécies vasculares. Jardim Botânico do Rio de Janeiro, Rio de Janeiro, v. 2.

Moran, R. C. \& Yatskievych, G. 1995. Pteridaceae. Pp. 104-105. In: R. C. Moran $\&$ R. Riba (eds.). Psilotaceae a Salviniaceae. In: G. Davidse, M. Sousa \& S. Knapp (eds.). Flora Mesoamericana. Universidad Nacional Autónoma de México, Ciudad de México, v. 1.

Mynssen, C. M. 1996. Ophioglossaceae. In: M. P. M. Lima \& R. R. Guedes-Bruni (orgs.). Reserva Ecológica de Macaé de Cima, Nova Friburgo-RJ, aspectos florísticos das espécies vasculares. Jardim Botânico do Rio de Janeiro, Rio de Janeiro, v. 2, p. 341-343. 
Mynssen, C. M. \& Sylvestre, L. S. 1996. Marattiaceae. In: M. P. M. Lima \& R. R. Guedes-Bruni (orgs.). Reserva Ecológica de Macaé de Cima, Nova Friburgo-RJ, aspectos florísticos das espécies vasculares. Jardim Botânico do Rio de Janeiro, Rio de Janeiro, v. 2, p. 273-277.

Pichi-Sermolli, R. E. G. 1996. Authors of scientific names in Pteridophyta. Royal Botanic Gardens, Kew.

Prado, J. \& Windisch, P. G. 2000. The genus Pteris L. (Pteridaceae) in Brazil. Boletim do Institu to de Botânica 13: 103-199.

Santos, M. G. 1996. Vittariaceae. In: M. P. M. Lima \& R. R. Guedes-Bruni (orgs.). Reserva Ecológica de Macaé de Cima, Nova Friburgo-RJ, aspectos florísticos das espécies vasculares. Jardim Botânico do Rio de Janeiro, Rio de Janeiro, v. 2, p. 441-443.

Santos, M. G \& Sylvestre, L. S. 1996. Schizaeaceae. In: M.P.M. Lima \& R. R. Guedes-Bruni (orgs.). Reserva Ecológica de Macaé de Cima, Nova Friburgo-RJ, aspectos florísticos das espécies vasculares. Jardim Botânico do Rio de Janeiro, Rio de Janeiro, v. 2, p. 427-432.

Smith, A. R. 1995. Pteridaceae. In: P. E. Berry, B. K. Holst \& K. Yatskievych (eds.). Pteridophytes, Spermatophytes: Acanthaceae-Araceae. In: J. A. Steyermark, P. E. Berry \& B. K. Holst (eds.). Flora of the Venezuela Guayana. Timber Press. Portland, v. 2, p. 12-22.

Sylsvestre, L. S. \& Kurtz, B. C. 1994a. Cyatheaceae. In: M. P. M. Lima \& GuedesBruni, R. R. (orgs.). Reserva ecológica de Macaé de Cima, Nova Friburgo-RJ, aspectos florísticos das espécies vasculares. Jardim Botânico do Rio de Janeiro, Rio de Janeiro, v. 1, pp. 139-152.

Sylsvestre, L. S. \& Kurtz, B. C. 1994 b. Dicksoniaceae. In: M. P. M. Lima \& GuedesBruni, R. R. (orgs.). Reserva ecológica de Macaé de Cima, Nova Friburgo-RJ, aspectos florísticos das espécies vasculares. Jardim Botânico do Rio de Janeiro, Rio de Janeiro, v. 1, p. 153-156.

Tryon, R. M. 1942. A revision of the genus Doryopteris. Contribution of the Gray Herbarium of Harvard University 143: 3-88.

Tryon, R. M. 1986. Some new names and new combinations in Pteridaceae. American Fern Journal 76(4): 184-186.

Tryon, R. M. \& Tryon, A. F. 1982. Ferns and allied plants, with special reference to Tropical America. Springer-Verlag. New York. 857p. 
